\title{
Comparison of Two Freezing Extenders and their Influence on Sperm Quality of Tunisian Arab stallions
}

\author{
Najjar A ${ }^{* 1}$, Ben Saïd $S^{2}$, Kalamoun $S^{2}$, Benaoun B ${ }^{3}$, Ezzaouia $M^{3}$, Chetoui $C^{4}$ and Ben Haj Aissa $S^{1}$ \\ ${ }^{1}$ National Institute of Agronomy, Tunisia \\ ${ }^{2}$ High School of Agricultural of Kef, Tunisia \\ ${ }^{3}$ National Stud Farm of Sidi Thabet, Tunisia \\ ${ }^{4}$ General Direction of Agricultural Production, Tunisia
}

${ }^{*}$ Corresponding author: Najjar A, National Institute of Agronomy, Tunisia, Fax: (+216) 71799391, Tel: (+216) 71287110, E-mail: amelnajarbenmatoug@gmail.com

Citation: Najjar A, Saïd SB, Kalamoun S, Benaoun B, Ezzaouia M, et al. (2016) Comparison of Two Freezing Extenders and their Influence on Sperm Quality of Tunisian Arab stallions. J Vet Sci Anim Husb 4(3): 302

Received Date: August 09, 2016 Accepted Date: November 22, 2016 Published Date: November 23, 2016

\begin{abstract}
The objective of the study was to evaluate semen quality of Tunisian Arab stallions frozen with 2 methods using 2 freezing basedextenders: the INRA $96^{\circ}$ or the INRA Freeze ${ }^{\circ}$. The semen was collected from 28 Tunisian Arab stallions and frozen following the previous methods. After thawing, the percentage of death spermatozoa, sperm motility parameters and morphology features were determined in both semen, frozen in the based-extender INRA $96^{\circ}$ or the INRA Freeze ${ }^{\oplus}$. The membrane integrity was determined only in the semen frozen in the INRA Freeze ${ }^{\circ}$. Results showed that motility parameters of post-thawed semen were better in the INRA96 than in the INRA Freeze ${ }^{\oplus}$ extender. However, abnormal sperm were higher in INRA96 $6^{\circ}$ than in INRA Freeze $e^{\star}$ extender $(\mathrm{p}<0.05)$. The statistical analysis showed, also, no variation for the percentage of death spermatozoa between the 2 based-extenders. Consequently, the use of the INRA Freeze ${ }^{\star}$ as a based-extender for Tunisian Arab stallions' frozen semen improved only sperm morphology and did not give us satisfactory results for sperm motility in comparison with the INRA96 ${ }^{\circ}$. Another in vivo assay is recommended in order to determine the effect of the two based-extenders on the pregnancy rate per cycle.
\end{abstract}

Keywords: Arab stallions; Semen quality; INRA96 ${ }^{\circ}$; INRA Freeze ${ }^{\circ}$ Thawing

\section{Introduction}

The frozen equine semen has been practised for several years with the use of some extenders. In fact, the first successful pregnancy carried with Barker and Grandier who froze the epididymal sperm cells using whole milk with 10\% of glycerol [1]. It has also been determined that milk and egg yolk are among the most frequently used extenders to freeze stallion's semen [2]. Kenney's extender was one of the former used for this purpose in the 70's. It should be prepared by ingredients in the laboratory [3]. After that in the 80 's, INRA 82 was also performed particularly with milk and egg yolk which have beneficial and detrimental effects on sperm cells [4]. The INRA 82 was used for artificial insemination with fresh cooled and frozen semen and gave satisfactory results. However, Kenney's extender was only used at that time for artificial insemination with fresh semen. Then in the 90's, Batellier, et al. developed INRA $96^{\circledR}$ containing phosphocaseinate instead of milk [5]. This one has maintained the sperm fertility during chilled storage at $4^{\circ} \mathrm{C}$ or $15^{\circ} \mathrm{C}[6]$. Moreover, when it was supplemented with egg yolk and glycerol during freezing, it gave an acceptable fertility per cycle in artificial insemination with frozen semen [7]. It was better approved of than the INRA 82 and has been the French conventional method for the freezing semen $[3,8]$. In recent years, Pillet, et al. developed a new extender for the freezing semen called INRA Freeze ${ }^{\varpi}$, a ready to use, for cryopreservation [9]. It is composed of INRA $96^{\varpi}$, sterilized egg yolk and glycerol [10]. They demonstrated that sterilized egg yolk has a cryopresevation function like the whole egg yolk. But they didn't report the fertility per cycle obtained with this latter. Whatever the used extender, unfortunately, several studies reported that there is a considerable variation between individual stallions in how well their semen retains its fertilizing capacity after freezing and thawing [11-13]. Katila and Vidament said that despite the improvement of knowledge and techniques in this field, there are some stallions whose semen cannot be frozen $[13,14]$.

The objective of our study was to evaluate two methods of freezing process of stallion's semen and their influence on spermatozoa quality using two different extenders: the INRA $96^{\circ}$ and the INRA Freeze ${ }^{\oplus}$. 


\section{Materials and Methods}

\section{Semen collection and evaluation}

Semen was collected from 28 Tunisian Arab stallions (mean age: $13 \pm 4.3$ years, total ejaculate: 56 ) using a Missouri artificial vagina (IMV, France) and mannequin with the presence of a mare. Each stallion was housed in an individual boxing in the National Stud Farm of Sidi Thabet in the north of Tunisia. Collections took place in the semen producing center of the stud farm of Sidi Thabet, from December 2012 to February 2013. The rhythm of collection was performed each 48 hours. After collection, the semen was immediately filtered to eliminate the gel fraction when it was present using a suitable filter as gauze with hydrophilic stitch. The volume of sperm was noted and the percentage of mobile sperm was determined using a contrast phase microscope (Leica, France) with a magnification $\mathrm{x} 40$ : a subjective estimate was carried out on a drop of sperm and placed between slide and cover [3]. Once this parameter was up to $70 \%$, the semen was frozen with 2 methods using 2 different freezing based-extenders.

\section{Experiment 1}

In this experiment, the semen was frozen as described by Haras Nationaux: the semen was firstly diluted in a skim milk and antibiotics Penicillin and Gentamicin at $+37^{\circ} \mathrm{C}(1 / 4$ semen, $3 / 4$ extender $)$, and put for 10 minutes in a water bath at $+22^{\circ} \mathrm{C}[3]$. Then, the semen was centrifuged at $600 \mathrm{~g}$ for 10 minutes. The supernatant was eliminated and the sperm pellet was diluted again in INRA $96^{\circledR}$ (200 ml, IMV, L'aigle, France) supplemented with $2.5 \%$ glycerol and $2 \%$ egg yolk to obtain a final sperm concentration of 100 millions $/ \mathrm{ml}$. The diluted semen was kept at $+4^{\circ} \mathrm{C}$ about 80 minutes. Then, the semen was identified and packaged in straws of 0.5 $\mathrm{ml}$. After that, straws were frozen with a cool mini digit which ensured the temperature decrease from $+4^{\circ} \mathrm{C}$ to $-140^{\circ} \mathrm{C}$ at the rate of $60^{\circ} \mathrm{C} /$ minute during 10 minutes. At the end of this stage, straws were immediately immersed in liquid nitrogen tank at $-196^{\circ} \mathrm{C}$.

\section{Experiment 2}

Semen was frozen following the same steps above. But, extenders were changed: at the first dilution, the semen was diluted in INRA $96^{\circ}$ while keeping the same rate of dilution. The second dilution was performed in INRA Freeze ${ }^{\circledast}$.

The protocol of the research in experiment 1 and 2 has been approved by the National Institute of Agronomy of Tunisia (INAT) and the National Foundation for the Improvement of the Horses Breed (FNARC).

\section{Semen evaluation after thawing}

For both experiments, the semen quality evaluation was performed after the freezing - thawing process: The percentage of dead spermatozoa was estimated by the use of an eosin - nigrosin stain at $6.9 \mathrm{pH}$, and counting a sample of 150 spermatozoa over the slide [15]. Besides, the sperm morphology features were studied from the unstained sample of semen fixed by a formaldehyde solution and observed by a phase-contrast microscope (Leica, Germany) [16].

The sperm motility was analyzed using Hamilton Thorn Motility Analyzer (HTM, version $12.1 \mathrm{M}$ ) as described by Varner, et al. [17]. For this purpose, 2 drops were put in the microcell chamber and analyzed for sperm mobility parameters including percentage of progressive sperm (\%PROG), average path velocity (VAP, $\mu \mathrm{m} / \mathrm{s}$ ), straight line velocity (VSL, $\mu \mathrm{m} / \mathrm{s}$ ) and curvilinear velocity $(\mathrm{VCL}, \mu \mathrm{m} / \mathrm{s})$. The $\%$ PROG was determined for $\mathrm{VAP}>30 \mu \mathrm{m} / \mathrm{s}$.

The membrane integrity of sperm cells was determined only on the semen frozen in the INRA Freeze ${ }^{\varpi}$ using the hypoosmotic swelling test (HOST) as described by Jeyendran and Van Der Van: The sperm cells were exposed to an hyposmotic Hank's Hepes solution (osmotic pressure $=50$ mosm) [18]. The sperm cells with functional membrane responded to the decreased osmotic pressure and shows cytoplasm droplets in their flagella. However, sperm cells with a damaged membrane had no response.

\section{Statistical analysis}

Data were analysed by Statistical Analysis System (SAS Institute Inc., Cary, NC, USA). General differences between means were tested by a factorial analysis for unbalanced data (GLM procedure of SAS). The comparison of sperm variables between the two methods were carried out using the DUNCAN test. Statistical significance was considered at $p<0.05$.

\section{Results}

\section{Sperm viability and motility in post frozen-thawed semen}

The percentage of death spermatozoa was $55 \pm 10 \%$ and $62 \pm 8 \%$ respectively when semen was frozen respectively in based-extender INRA96 ${ }^{\circ}$ and INRA Freeze ${ }^{\oplus}$ (Figure 1 ).

The sperm motility parameters, evaluated by computer-assisted sperm analysis CASA, were higher in based-extender INRA96 ${ }^{\circ}$ than those found in the INRA Freeze ${ }^{\varpi}$ (Figure 2 and Figure 3 ). The statistical analysis showed that the percentage of progressive sperm, average path velocity, the curvilinear velocity were significantly higher in the semen frozen in the based-extender INRA96 $(\% \mathrm{PROG}=26.5 \pm 13.2$ vs $17 \pm 11.8 \%, \mathrm{p}<0.0001 ; \mathrm{VAP}=91 \pm 22$ vs $75 \pm 25 \mu \mathrm{m} / \mathrm{s}, \mathrm{p}<0.0001 ; \mathrm{VCL}=165 \pm 20 v s 130 \pm 34 \mu \mathrm{m} / \mathrm{s}, \mathrm{p}<0.0001)$. 
However, no variation was found for the straight line velocity in the semen frozen in the two extenders (VSL $=74 \pm 12 v s 68 \pm 21$ $\mu \mathrm{m} / \mathrm{s}, \mathrm{p}>0.05)$.

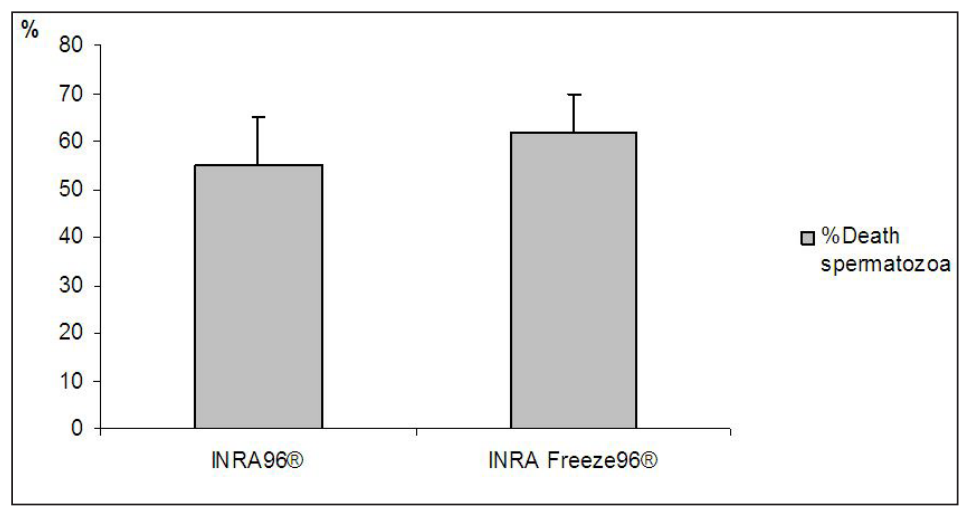

Figure 1: Percentage of death spermatozoa after semen thawing

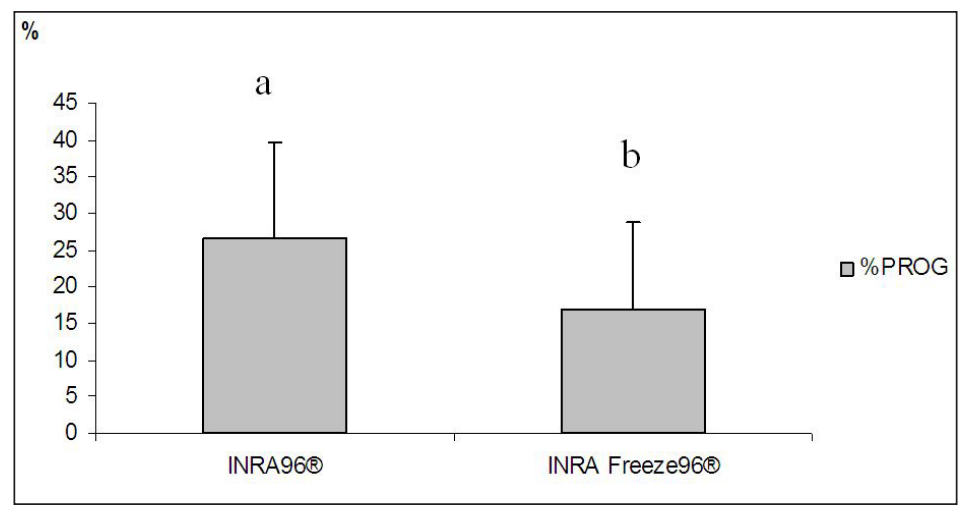

\%PROG: percentage of progressive sperm $a, b: p<0.0001$

Figure 2: Percentage of progressive sperm after semen thawing.

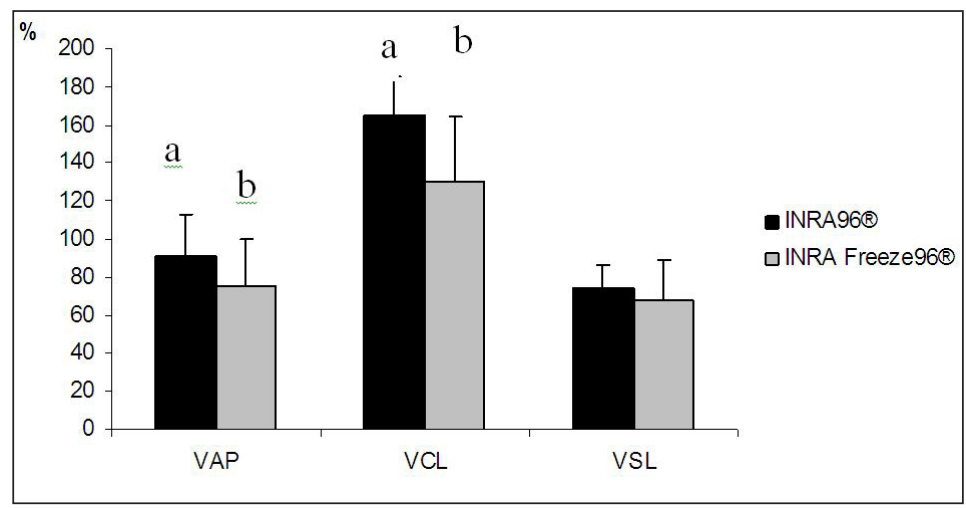

VAP: average path velocity; VCL: curvilinear velocity; VSL: straight line velocity $a, b: p<0.0001$

Figure 3: Sperm velocity after semen thawin

\section{Sperm morphology features in post frozen-thawed semen}

The percentage of total abnormal sperm (\%TAS) was higher for semen frozen in the INRA96 ${ }^{\star}$ than in INRA Freeze extender $^{\bowtie}$ (\%TAS $=51 \pm 15.2$ vs $26.1 \pm 9.7 \%, \mathrm{p}<0.001$; Figure 4$)$. The difference was showed also for all classes of sperm features studied (Figure $5)$ : the percentages of abnormal head (\%AH), cytoplasmic droplets (\%CD), abnormal mid pieces (\%MP) and abnormal flagella $(\% \mathrm{AF})$ were higher for the semen frozen in the INRA96 $6^{\circ}$ than in the INRA Freeze ${ }^{\circledast}$ based-extender $(\% \mathrm{AH}=3.1 \pm 1.2 v s 0.5 \pm 0.1 \%$, $\mathrm{p}<0.001 ; \% \mathrm{CD}=13 \pm 4.8$ vs $7.2 \pm 3.3 \%, \mathrm{p}<0.001 ; \% \mathrm{MP}=9.8 \pm 5.1$ vs $6.8 \pm 3.7 \%, \mathrm{p}<0.0001 ; \% \mathrm{AF}=25 \pm 5.2$ vs $11.8 \pm 4.4 \%, \mathrm{p}<0.0001)$.

\section{Membrane integrity of sperm cells}

The percentage of sperm cells with intact membrane in the ejaculate frozen was $22 \pm 1.2 \%$ in total ejaculate frozen with the INRA Freeze ${ }^{\circledast}$ based-extender. 

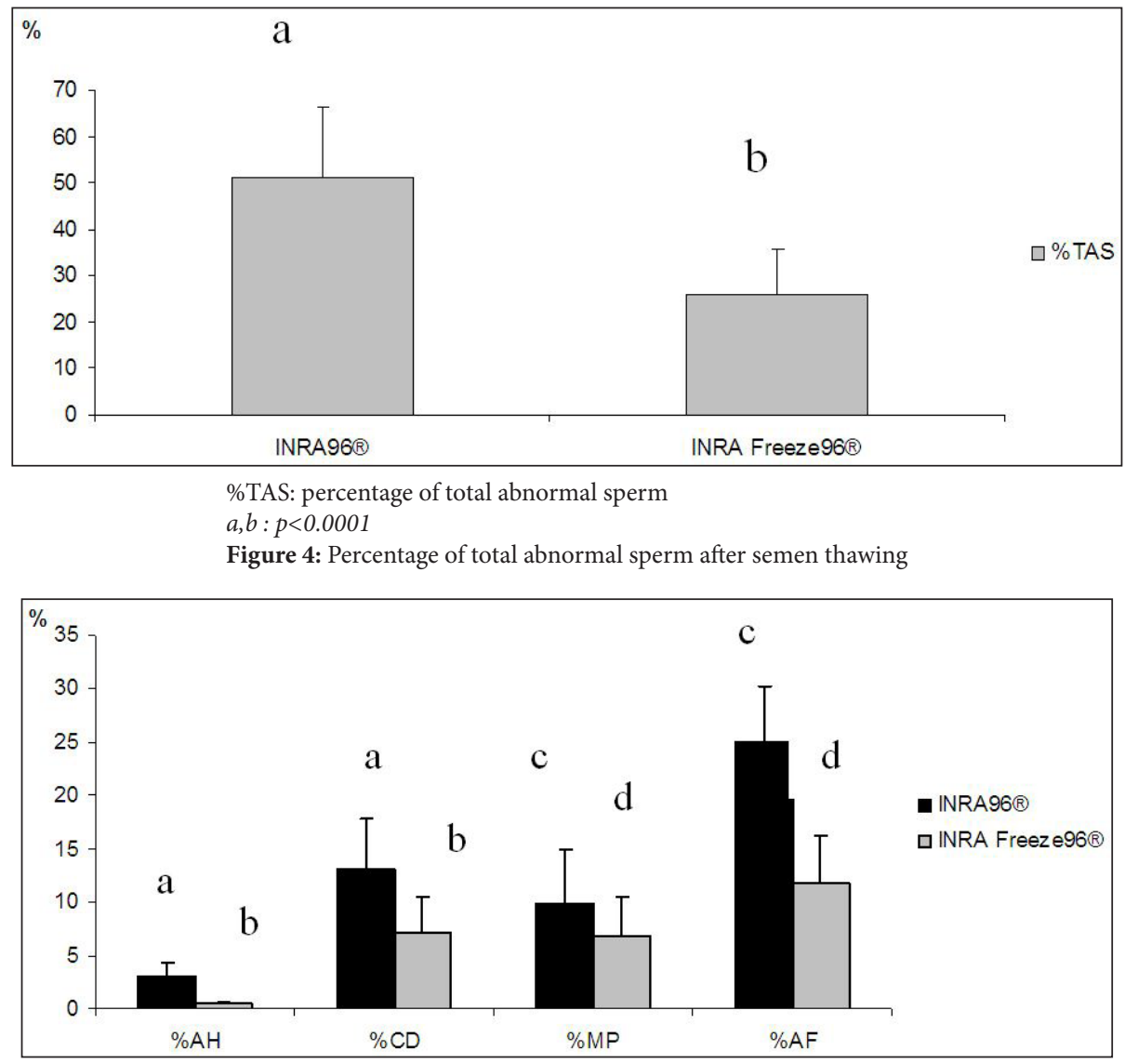

$\% \mathrm{AH}$ : percentage of abnormal head; \%CD: percentage of cytoplasma droplets; \%MP: percentage of abnormal mid piece; \%AF: percentage of abnormal flagella $a, b: p<0.001 ; c, d: p<0.001$

Figure 5: Sperm morphology features after semen thawing.

\section{Discussion}

This study showed that motility of post-thawed sperm cells was better in the INRA96 than in the INRA Freeze based-extender. However, abnormal sperm were higher in INRA96 ${ }^{\circ}$ than in INRA Freeze ${ }^{\circ}$ based-extender. Our results do not agree with those reported by Barenton, et al. [10]. In fact, in their in vivo study comparing INRA Freeze with INRA96 ${ }^{\circ}$ supplemented with liposomes in egg yolk plasma, they found no differences between the two extenders for the pregnancy rate per cycle. Furthermore, Pillet, et al. demonstrated that INRA Freeze ${ }^{\circ}$ which was composed of INRA96 $6^{\circ}$ supplemented with sterilized egg yolk plasma improved fertility after insemination with the frozen semen [9]. But, they previously found that this latter didn't improve sperm motility parameters and membrane integrity compared to the INRA82 extender [8].

Besides, the result of the percentage of sperm cells with intact membrane was considered low in this study when the semen was frozen with INRA Freeze. Pillet, et al. studying the response profiles of spermatozoa exposed to a range of hypotonic steps found high values of sperm reaction for the semen frozen with INRA $96^{\circ}$ supplemented with egg yolk and glycerol and acceptable values for the semen frozen with INRA82 [8].

In this case, the lowest values of the sperm motility parameters and membrane integrity in the method of freezing semen using INRA Freeze ${ }^{\circ}$ based-extender could be attributed to the absence of the skim-milk compared to the other method using INRA96 and skim-milk. Indeed, Batellier, et al. reported that milk with its components can be either beneficial or harmful for sperm cells [19]. Plante, et al. said that skim-milk can protect sperm during storage [20].

\section{Conclusion}

This study showed that the use of the INRA Freeze ${ }^{\bullet}$ as a based-extender for the frozen semen of Tunisian Arab stallions improved sperm morphology but it did not give us satisfactory results for sperm motility and membrane integrity in comparison with the INRA96. Another in vivo assay is recommended in order to determine the effect of the two based-extenders on the pregnancy rate per cycle.

\section{Acknowledgements}

The study was financed by the National Stud Farm of Sidi Thabet. 


\section{References}

1. Barker CAV, Grandier JCC (1957) Pregnancy in A mare resulting from frozen epididymal spermatozoa. Can J Comp Med Vet Sci 21: 47-51.

2. Samper JC, Morris CA (1998) Current methods for stallion semen cryopreservation: a survery. Theriogenology 49: 895-903.

3. Nationaux H (2004) Insémination artificielle équine. Guide pratique. ( $3^{\text {rd }}$ ed) Direction des connaissances, ENPH, 61310 Le Pin au Haras, France.

4. Magistrini M, Couty I, Palmer E (1992) Factors influencing stallion sperm survival. Acta Vet Scand 88: 97-110.

5. Batellier F, Magistrini M, Fauquant J, Palmer E (1997) Effect of milk fractions on survival of equine spermatozoa. Theriogenology 48: 391-410.

6. Chanavat E, Vidament M, Defoin L, Duchamp G, Levillain N, et al. (2005) Effect of storage and temperature on in vitro stallion sperm parameters and fertility rate. Anim Reprod Sci 89: 318-21.

7. Magistrini M (1999) L'insémination artificielle chez les équins. INRA Prod Anim 12: 347-9.

8. Pillet E, Batellier F, Duchamp G, Furstoss V, Le Vern Y, et al. (2008) Freezing stallion semen in INRA96 ${ }^{\circ}$-based extender improves fertility rates in comparison with INRA82. Dairy Sci Technol 88: 257-65.

9. Pillet E, Duchamp G, Batellier F, Yvon JM, Delhomme G, et al. (2009) A new freezing extender for stallion semen to get high fertility rates. In: Book of abstract of the $60^{\text {th }}$ annual meeting of EAAP 304 .

10. Barenton M, Couty I, Labbé C, Méa-Batellier F, Duchamp G, et al. (2011) Liposomes of phospholipids, a promising approach for stallion sperm freezing. In: Book of abstracts of the $62^{\text {nd }}$ Annual Meeting of the European Federation of Animal Science 40.

11. Tischner M (1979) Evaluation of deep-frozen semen in stallions. J Reprod Fert 27: 53-9.

12. Vidament M, Dupere AM, Julienne P, Evain A, Noue P, et al. (1997) Equine frozen semen: freezability and fertility field results. Theriogenology $48: 907-17$.

13. Vidament M (2005) French field results (1985-2005) on factors affecting fertility of frozen stallion semen. Anim Reprod Sci 89: 115-36.

14. Katila T (2001) In vitro evaluation of frozen-thawed stallion semen: A review. Acta Vet Scand 42: 199-217.

15. Sieme H, Echte A, Klug E (2002) Effect of frequency and interval of semen collection on seminal parameters and fertility of stallions. Theriogenology $58: 313-6$.

16. Jasko DJ (1992) Evaluation of stallion semen. Vet Clin North Am Equine Pract 8: 129-48.

17. Varner DD, Scott DV, Johnson L (1991) Use of the computerized system for evaluation of equine spermatozoal motility. Am J Vet Res 52: 224-30.

18. Jeyendran RS, Van Der Ven HH, Zaneveld LJ (1992) The hypoosmotic swelling test: an update. Arch Androl 29: 105-16.

19. Batellier F, Duchamp G, Vidament M, Arnaud G, Palmer E, et al. (1998) Delayed insemination is successful with a new extender for storing fresh equine semen at 15 degrees $C$ under aerobic conditions. Theriogenology 50: 229-36.

20. Plante G, Luzignan MF, Lafleur M, Manjunath P (2015) Interaction of milk proteins and binder of sperm (BSP) proteins from boar, stallion and ram semen. Reprod Biol Endocrinol 13: 92.

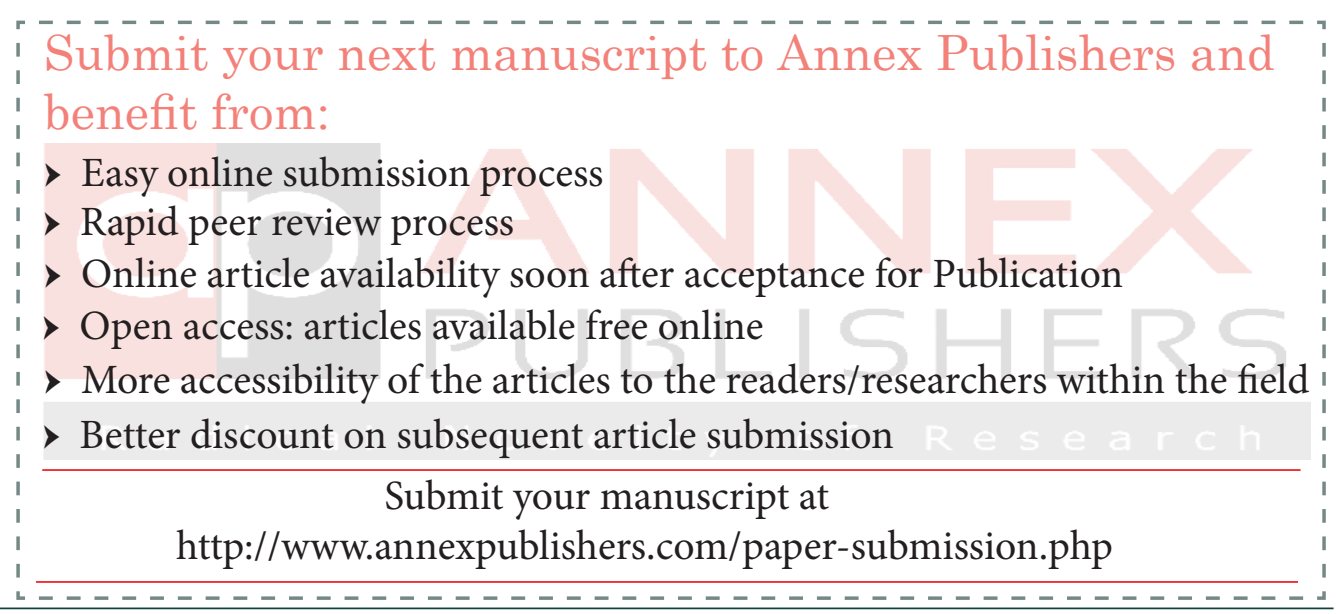

